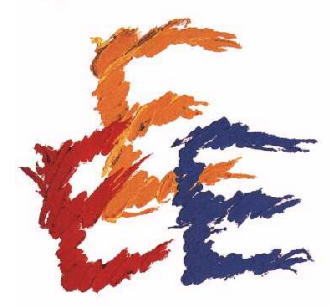

Fondazione Eni Enrico Mattei

\title{
Forest Resource Extraction by \\ Local Communities: \\ A Comparative Dynamic Analysis
}

\author{
Herath M.Gunatilake* and \\ Ujjayant Chakravorty** \\ NOTA DI LAVORO 41.2000
}




\title{
FOREST RESOURCE EXTRACTION BY LOCAL COMMUNITIES: A COMPARATIVE DYNAMIC ANALYSIS
}

\section{By}

Herath M. Gunatilake and Ujjayant Chakravorty*

\begin{abstract}
Much of the world's gene pool is located in tropical rainforests, which are being destroyed at an alarming rate. Proper management of protected forests is crucial to avoid further loss of forest resources and biodiversity. Resource extraction by local communities has been cited as a major impediment to the efficient management of protected forests. This paper develops a two sector dynamic model for agriculture and forest resource extraction which suggests that agricultural development in the periphery of protected forests may be an effective strategy for forest protection. Comparative dynamic results show that higher prices for agricultural output, lower input prices, better knowledge of agricultural production techniques and a lower rate of individual time preferences result in higher equilibrium stock of forest resources. Tobit analysis with data collected from the Sinharaja forest in Sri Lanka provides supportive empirical evidence.
\end{abstract}

Key words: Comparative dynamics, Forest protection, Sri Lanka, Tobit analysis, Tropical rainforests

JEL Classification: Q23, Q12, Q28

*Respectively, Department of Agricultural Economics, University of Peradeniya, Sri Lanka, and Department of Economics, Emory University, Atlanta. Corresponding author: Ujjayant Chakravorty, Department of Economics, Emory University, Atlanta, GA 30322, USA, unc@emory.edu 


\section{FOREST RESOURCE EXTRACTION BY LOCAL COMMUNITIES: A COMPARATIVE DYNAMIC ANALYSIS}

\section{Introduction}

It is universally known that tropical rainforests are being degraded at an alarming rate (e.g., see Buchholz, 1993). These forests covering a total area of nearly 5 million square miles, that lie between the Tropics of Cancer and Capricorn, are a vital source of raw materials such as timber, fuelwood, oils and drugs. More importantly, they are home to several millions of plant and animal species - more than are found in any other terrestrial ecosystem. Preservation of these rainforests is important for a host of reasons, but most critically, because these genetic materials are irreplaceable and are disappearing at a rapid rate. In the past 400 years, some 486 animal and 654 plant species have been recorded as having become extinct while many more are threatened with extinction (UNEP, 1995, p.716). Equally significant is the fact that worldwide, nearly 700 million people are estimated to live in the periphery of these rainforests and are heavily dependent on them for survival (Guppy, 1984).

Historically, there have been two major causes for the destruction of tropical rainforests. First, much prime forest land has been lost from conversion to farmland and encroachment by settlers (Barbier, 1993). Second, logging and extraction of forest products by commercial and local interests have been an important cause of deforestation (Repetto 1990; Barbier 1993, World Bank, 1993). Excessive logging has led to reduction of forest cover, creating appropriate conditions for encroachment and habitation (Poore and Sayer, 1991).

Expansion of agriculture may continue to be the major cause of the loss of biodiversity in countries such as Brazil which has large tracts of land under forests. However, in many developing countries, only a few natural rainforests remain intact and encroachment possibilities are limited (Repetto and Gillis, 1988). In response to the concern over tropical rainforest destruction, governments in developing countries - where most of these forests are located - have often reacted through policy measures that designate certain forest areas as protected forests (e.g., national wilderness areas, national parks, world heritage sites, wildlife reserves, etc.) and have passed legislation that restrict use of these forest resources. As a result, there are now over 8,500 distinct protected areas covering about 800 million hectares of land in the world (World Resources Institute, 1994) mostly located in developing countries. In these protected areas, forest resource utilization by local communities seems to be the principal problem faced by managers (Hough, 1988; Wells, 1992; Ghimire, 1994; Nepal and Weber, 1995; Studsrod and Wegge,1995).

Economists have argued that government policies which promote agriculture are responsible for the loss of forests and biodiversity. For example, Deacon (1995) used a general equilibrium model to show that government policies that reduce profitability of agriculture reduce deforestation. Ehui et 
al (1990) suggest that greater returns to agriculture accelerate deforestation in a dynamic model of resource extraction. In both these studies, agricultural output is assumed to be an increasing function of deforestation. While this assumption accurately represents the expansion of farming into new forest areas, it may not hold in many developing countries where the natural forest cover has already declined to critically low levels (Repetto and Gillis, 1988) and free forestry-agricultural frontiers have ceased to exist.

In particular, the assumption that agricultural production is an increasing function of deforestation may not hold for protected forests in which the boundaries have been well demarcated, buffer zones between the forest and the surrounding villages established and laws have been enacted to prevent conversion of forest lands to agriculture. A distinction needs to be made between the effectiveness of legal measures in preventing conversion of forest lands to agriculture and local extraction of forest resources. Activities relating to the conversion of forest lands to farming are clearly visible, can be monitored at relatively low cost, and can be easily attributed to those responsible (Gunatilake, 1988; Ministry of Forestry and Environment of Sri Lanka, 1995). Therefore, legal and punitive measures may be effective in controlling the conversion of forest land to agriculture. In sharp contrast, forest resource extraction activity is not easily detected and legislative measures have not been very effective in controlling it (Leader-Williams and Albon, 1990; Barret and Arcese, 1995; Gunatilake, 1998). In this paper, we have therefore modeled forest resource extraction in a protected forest where conversion of forest lands is not allowed yet resource extraction by local communities continues unchecked.

We develop a dynamic model that integrates forest resource extraction and farming. The relationship between agricultural activities in the forest periphery and resource extraction in the protected forest are explicitly modeled through labor allocation between these activities. A comparative dynamic analysis is performed on the equilibrium solution to obtain the effect of exogenous parameters on the time path of shadow prices and the equilibrium forest stock. The results suggest that higher agricultural output prices, lower input prices, and improved production technology result in an increased stock of forest resources. Finally, we provide supportive empirical evidence through an econometric analysis of household data from the Sinharaja forest reserve in Southern Sri Lanka.

Our results suggest that forest conservation measures need to be accompanied by agricultural development in the peripheral communities. That is, a concerted effort to promote agriculture in the periphery, together with legal measures to prevent the conversion of forest lands into agriculture, may induce the local community to reduce its dependency on forest resources. Although agriculture is traditionally viewed as a destructive force and is a major contributor to deforestation through encroachment of farming activity into forest lands, our approach suggests that conservation of forests must be accompanied by modernization of subsistence agriculture in the vicinity of the protected 
forests. Thus, we propose an integrated approach in which conservation objectives are achieved through agricultural development and not merely by restricting community access to forest resources.

The rest of the paper is organized as follows. Section II develops a dynamic model of forest resource extraction and derives the associated optimality conditions. Section III details the comparative dynamic analysis. Section IV presents empirical tests of the theory. Finally, section V concludes the paper.

\section{The Model}

We develop a time allocation model of a representative household located at the periphery of a protected forest. To this end, let us assume that the household is engaged in two distinct economic activities, namely, forest resource extraction and agriculture. For simplicity, the household is assumed to extract a single forest product which is marketable. In reality, forest resources include both timber as well as non-timber forest products such as fuelwood, fruits, spices, oils resins and medicinal materials. In most protected areas timber harvesting by local communities is seldom allowed while significant illegal timber smuggling can be controlled through enforcement. Thus, although the following analysis is applicable when extended to include timber extraction, forest resources in this paper generally refer to non-timber forest products (NTFP). We avoid dealing with the extraction of multiple forest products by assuming that these joint products can be aggregated into a single product that is collected by the household and sold for cash income. The aggregation issue becomes important in the empirical section and is discussed further there. We use a Faustmann type dynamic growth specification to represent the growth of the single aggregated stock of forest biomass. Implicitly we are assuming away differential growth rates for the distinct forest products. To this end, define $x(t)$ as the forest resource stock, $x(t)>0$, and assume that the initial stock size is known to be $x_{0}>0$. Then the standard growth function for this aggregated forest biomass when there is no harvesting is given by:

$$
\dot{x}(t)=F(x(t), \gamma, K)
$$

where $\gamma$ denotes the intrinsic growth rate of the forest biomass assumed constant, $K$ is the carrying capacity of the forest and $F(x)$ is the growth rate of biomass, and is non-negative for $0<x<K$. As is common in the literature, the explicit form of the growth function is expressed by the standard logistic form $F(x(t), \gamma, K)=\gamma x\left(1-x K^{-1}\right)$. The household allocates its labor between farming and forest extraction. Without loss of generality, let the labor endowment per household be unity of which $L$ units are allocated to collecting forest products and (1-L) to agriculture. For notational convenience we denote the latter as $L a$ (i.e., $L a=1-L$ ). The household is assumed to produce a single agricultural product for the market. Multiple products from farming could be incorporated but would make the model unnecessarily complex. The crop production function for the household is given by: 


$$
\begin{aligned}
& Q(t)=Q(L a(t), I(t), a(t)), \\
& Q_{L a}>0, Q_{L a L a}<0, Q_{I}>0, Q_{I I}<0, Q_{L a I}>0, \\
& Q_{\alpha}>0, Q_{\alpha \alpha}<0, Q_{\alpha L a}>0, Q_{\alpha I}>0,
\end{aligned}
$$

where $Q(t)$ is agricultural output at any instant $t, I(t)$ is the quantity of purchased inputs such as fertilizers and pesticides and $\alpha(t)$ is a coefficient that represents the level of knowledge of agricultural production techniques. This coefficient is an index that depends on several factors such as research and development expenditures in agriculture, the effectiveness of agricultural extension activities, experience in farming and formal education of the farmer. The production function is $C^{2}$ and is strictly concave in $L a$ and $I$., i.e. $Q_{L a L a} Q_{I I}-Q^{2}{ }_{L a I}>0$ where $Q_{L a}$ denotes the derivative $\partial Q(t) / \partial L a(t)$ and $t$ is dropped to avoid notational clutter. The positive partial derivatives and negative second order derivatives indicate that agricultural production increases at a decreasing rate with both labor and purchased input. The positive cross partial derivative suggests that higher levels of both purchased input and knowledge of agricultural practices increase the marginal productivity of labor. Similar assumptions on the cross partials of the production function have been made by LaFrance (1992) and Ehui, Hertel and Preckel (1990).

Our model only considers family labor. In reality, limited quantities of hired labor may sometimes be used in the type of subsistence farming scenario considered here. However, in the present analysis this possibility is assumed away for simplicity. Then the harvest function of the forest biomass is given by:

$$
\begin{aligned}
& h(t)=h(x(t), L(t)), \\
& h_{x}>0, h_{x x}<0, h_{L}>0, h_{L L}<0, h_{L x}=0,
\end{aligned}
$$

where $h(t)$ is the instantaneous harvest of forest stock.. Partial derivatives of the harvest function indicate that harvest is an increasing function of both labor and forest resource stock, and subject to diminishing returns. We further assume that the marginal product of labor is not affected by the stock - $h_{L x}$ equal to zero - a plausible assumption that simplifies the comparative dynamics. Household income at any given instant $t, Y(t)$, is given by:

$$
Y(t)=p^{a} Q\left((L a(t), I(t), \alpha(t))-p^{I} I(t)+p^{f} h(x(t), L(t))\right.
$$

where $p^{a}$ is the output price of the agricultural product, $p^{f}$ is the price of the marketed forest product and $p^{I}$ is the price of the purchased input for agriculture. Then the representative household's maximization problem can be written as:

$$
V(\beta)=\operatorname{Max}_{L, I} \int_{0}^{T} e^{-r t} Y(t) d t
$$




$$
\begin{aligned}
& \text { subject to } \dot{x}(t)=F(x(t), \gamma, K)-h(x(t), L(t)), \text { and } \\
& x(0)=x_{0}
\end{aligned}
$$

where $r$ is the discount rate, $T$ is the finite planning horizon and $\beta=\left(p^{a}, p^{f}, p^{I}, r, \alpha, \gamma, K\right)$ is the vector of exogenous parameters. The choice variables are the time allocated to forestry, which automatically determines the time spent on farming, and the amount of input use. The current value Hamiltonian for (5) is:

$$
H=p^{a} Q(L a, I, \alpha)-p^{I} I+p^{f} h(x, L)+\lambda\{F(x, \gamma, k)-h(x, L)\}
$$

where $\lambda(t)$ is the usual co-state variable attached to the differential equation (1). The corresponding necessary conditions are derived as below:

$$
\begin{aligned}
& \partial H / \partial I=p^{a} Q_{I}-p^{I}=0, \\
& \partial H / \partial L=-p^{a} Q_{L a}+p^{f} h_{L}-\lambda h_{L}=0, \text { and } \\
& \dot{x}=F(x, \gamma, K)-h(x, L) .
\end{aligned}
$$

The time path of the co-state variable is given by:

$$
\dot{\lambda}(t)=r \lambda-\left\{p^{f} h_{x}+\lambda\left(F_{x}-h_{x}\right)\right\}
$$

and the transversality conditions are:

$$
\begin{aligned}
& x(0)=x_{0}, \text { and } \\
& \lambda(T) \geq 0, x(T) \geq 0, \lambda(T) x(T)=0 .
\end{aligned}
$$

In order to verify that the above conditions are also sufficient, we need to check that the Hamiltonian is concave in $\mathrm{L}$ and $\mathrm{I}$, that is:

$$
\begin{aligned}
H_{I I} H_{L L}-\left(H_{I L}\right)^{2} & =p^{a} Q_{I I}\left(Q_{I I} Q_{L a L a}+\left(p^{f}-\lambda\right) h_{L L}-\left(Q_{I L}\right)^{2}\right. \\
& =\left(p^{a}\right)^{2}\left(Q_{I I} Q_{L a L a}-\left(Q_{I L}\right)^{2}\right)+p^{a} Q_{I I}+\left(p^{f}-\lambda\right) h_{L L}>0
\end{aligned}
$$

which follows from the concavity of the agricultural production function and that $\left(p^{f}-\lambda\right)>0$, obtained from rewriting (7.2) and using the fact that $h_{L}>0$ and $Q_{L a}>0$. Thus, strict concavity in (8) implies that a unique solution for the control problem exists.

The above conditions can be interpreted as follows. Equation (7.1) equates the marginal benefit of an incremental increase in purchased inputs to its marginal cost (price). Similarly, equation 
(7.2) equates the marginal benefit of the labor input in forest extraction to its marginal cost. The latter has two components - the first is the foregone marginal benefit ( $p^{a} Q_{L a}$ ) of not employing labor in farming, and the second $\left(\lambda h_{L}\right)$ is the opportunity cost of harvesting the forest resource today as opposed to keeping it for future use. Equation (7.2) also suggests that $\left(p^{f}-\lambda\right) h_{L}=p^{a} Q_{L a}>0$ implying that the shadow price of forest resource stock must be less than the price of the forest product. Thus $p^{f}$ should compensate both for the foregone agricultural income due to allocation of labor in forestry and the foregone benefits from not conserving the forest resource in the next period.

Equation (7.3) needs no interpretation while (7.4) can be rearranged as: $r \lambda-\dot{\lambda}+\lambda h_{x}=p^{f} h_{x}+\lambda F_{x}$. The right hand side represents the benefits from harvesting which consist of two components - the direct benefit from harvesting in the current period $\left(p^{f} h_{x}\right)$ and the indirect benefit from incremental growth of the stock $\left(\lambda F_{x}\right)$. However, the term $\lambda F_{x}$ can be a benefit or a cost depending on the equilibrium stock at which harvesting takes place, i.e., whether the stock is to the left or to the right of the maximum sustainable yield (MSY). If equilibrium harvesting takes place to the left of MSY, this term is positive and hence a benefit because it leads to higher incremental growth. On the other hand, harvesting to the right of the MSY suggests that marginal extraction would reduce the growth rate of the stock and is a "cost." The left hand side of the last equation represents the cost of extraction. It includes an interest charge term $(r \lambda)$, a capital gains term $(-\dot{\lambda}(t))$, and foregone benefits of future harvests, $\lambda h_{x}$.

\section{Comparative Dynamics}

In this section we follow the method outlined by Caputo (1990a, 1990b) to derive comparative dynamics results. This involves simultaneously solving the necessary conditions (7.1-7.2) so that (7.17.6) are reduced to a pair of ordinary differential equations. Since $\frac{\partial}{\partial(L, I)}\left(H_{L}, H_{I}\right)^{\prime}$ does not vanish over the entire domain, (7.1-7.2) can be solved globally and uniquely using Gale and Nikaido (1965) for $L=\hat{L}(\lambda, \delta)$ and $I=\hat{I}(\lambda, \delta)$ where $\delta=\left(p^{a}, p^{f}, p^{I}, \alpha\right)$ (see Appendix for details) and yield the following comparative static results:

$$
\begin{aligned}
& \frac{\hat{d I}}{d p^{a}}=\frac{-Q_{I}\left\{p^{a} Q_{L a L a}+\left(p^{f}-\lambda\right) h_{L L}\right\}+p^{a} Q_{L a} Q_{I L a}}{|B|}>0, \\
& \hat{d} \\
& \frac{d p^{f}}{d}=-\frac{p^{a} h_{L} Q_{I L a}}{|B|}<0,
\end{aligned}
$$




$$
\begin{aligned}
& \frac{\hat{d I}}{d p^{I}}=\frac{p^{a} Q_{L a L a}+\left(p^{f}-\lambda\right) h_{L L}}{|\mathrm{~B}|}<0, \\
& \frac{\mathrm{d} I}{\mathrm{~d} \alpha}=\frac{-p^{a} Q_{I \alpha}\left\{p^{a} Q_{L a L a}+\left(p^{f}-\lambda\right) h_{L L}\right\}+\left(p^{a}\right)^{2} Q_{I L a} Q_{L \mathrm{a} \alpha}}{|B|}>0 \text {, and } \\
& \frac{\hat{\mathrm{d} I}}{\mathrm{~d} \lambda}=\frac{p^{a} h_{L} Q_{I L a}}{|B|}>0 .
\end{aligned}
$$

The above results are intermediate and will be used later in this section to obtain comparative dynamic results: however, their interpretation is intuitively appealing and help illuminate the relationship between labor allocation, forest resource extraction and farming. For example, (9.1) and (9.2) suggest that an increase in the price of the agricultural product will increase the use of purchased inputs whereas an increase in the price of the forest resource will reduce purchased input use. Thus when forestry becomes more attractive, i.e., the price of the forest product increases, it leads to a "contraction" in farming activity. From (9.3), an increase in the price of purchased inputs in farming reduces its use by households. Condition (9.4) suggests that increased knowledge of farming practices results in a higher use of purchased inputs. Finally, a higher shadow price of the forest biomass increases the opportunity cost of harvesting forest resources and therefore reduces the labor allocated to extraction (see 9.5). This extra labor released from forestry is used up in farming. Thus, a higher shadow price of the forest resource stock leads to intensification of agriculture and diverts labor away from extracting forest resources.

Further intermediate comparative static results are obtained as follows:

$$
\frac{d \hat{L}}{d p^{a}}=\frac{p^{a} Q_{I I} Q_{I L a}-p^{a} Q_{I L a} Q_{I}}{|B|}<0,
$$$$
\frac{\hat{d L}}{d p^{f}}=-\frac{p^{a} Q_{I I} h_{L}}{|B|}>0,
$$$$
\wedge
$$$$
\frac{d L}{d p^{I}}=\frac{p^{a} Q_{I L a}}{|B|}>0,
$$

$$
\frac{\mathrm{d} \hat{L}}{\mathrm{~d} \alpha}=\frac{\left(p^{a}\right)^{2} Q_{I I} Q_{L \mathrm{La} \alpha}-\left(p^{a}\right)^{2} Q_{I L a} Q_{I \alpha}}{|B|}<0, \text { and }
$$

$$
\frac{\hat{\mathrm{d}} \hat{L}}{\mathrm{~d} \lambda}=\frac{p^{a} Q_{I I} h_{L}}{|B|}<0 \text {. }
$$


From (9.6) and (9.7), an increase in the price of the agricultural product leads to higher labor allocation in agriculture thereby reducing labor use in forest extraction, whereas an increase in the price of the forest product will lead to more labor use in forestry. An increase in agricultural input prices makes farming less intensive and leads to increased labor use in forestry. Improved knowledge of farming techniques leads to a shift in household labor use from forest harvesting to farming. Finally, higher shadow prices of the forest resource stock increases the opportunity cost of forest extraction so that the representative household will allocate less labor in forestry extraction.

Substitution of the identities $L \equiv \hat{L}(\lambda, \delta)$ and $I \equiv \hat{I}(\lambda, \delta)$ in (7.3) and (7.4) reduces the latter to

$$
\begin{aligned}
& \dot{\lambda}=r \lambda-\left\{p^{f} h_{x}(x, \hat{L}(\lambda, \delta))+\lambda\left(F_{x}(x, \gamma, K)-h_{x}(x, \hat{L}(\lambda, \delta)\},\right.\right. \\
& \dot{x}=F(x, \gamma, K)-h(x, L(\hat{\lambda}, \delta)), \\
& x(0)=x_{0}, \text { and } \\
& \lambda(T) \geq 0, x(T) \geq 0, \lambda(T) x(T)=0 .
\end{aligned}
$$

The next step in comparative dynamic analysis is to insert the solution to (10.1-10.4), $x(t, \beta)$ and $\lambda(t, \beta)$, back into $(10.1-10.4)$ to produce the following identities:

$$
\begin{aligned}
& \dot{\lambda}(t, \beta) \equiv r \lambda(t, \beta)-\left\{p^{f} h_{x}(x(t, \beta), \hat{L}(\lambda, \delta))+\lambda(t, \beta)\left(F(x(t, \beta), \gamma, K)-h_{x}(x(t, \beta), \hat{L}(\lambda, \delta)\},\right.\right. \\
& \dot{x}(t, \beta) \equiv F(x(t, \beta), \gamma, K)-h(x(t, \beta), \hat{L}(\lambda, \delta)), \\
& x(0, \beta) \equiv x_{0}, \text { and } \\
& \lambda(T, \beta) \geq 0, x(T, \beta) \geq 0, \lambda(T, \beta) x(T, \beta) \equiv 0 .
\end{aligned}
$$

The variational differential equations were then derived by differentiating the system of ordinary differential equations ((11.1) and (11.2)), and the associated boundary conditions with respect to the parameters of interest and evaluating the derivatives at $\beta=\beta^{0}$. The boundary conditions of (11.4) represent two natural conditions: (i) $\lambda(T, \beta)>0 \Rightarrow x(T, \beta) \equiv 0 \quad$ and (ii) $x(T, \beta)>0 \Rightarrow \lambda(T, \beta) \equiv 0$. In the first case the local community harvests the forest resource to depletion within the planning period. The second case suggests that there will be a positive stock of forest left in the terminal period in which case the shadow price at terminal time will be zero. Given that we are modeling resource extraction in a protected forest, complete depletion of resources within the planning horizon may be an extreme case to consider. We thus limit the following comparative dynamic analysis to the second case, i.e., a strictly positive forest biomass at the terminal time period.

In the following sections, comparative dynamics results are derived using perturbed phase diagram analysis. In determining the direction of motion in the phase diagrams (see figure 1) assume 
signs for $\left(x_{p}{ }^{a}, \lambda_{p}{ }^{a}\right)$, use this assumption and the signs of $a_{i j} i, j=1,2$ to determine the signs $\left(\dot{x}_{p}{ }^{a}, \dot{\lambda}_{p}{ }^{a}\right)$, and use the signs of $\left({\dot{x_{p}}}^{a}, \dot{\lambda}_{p}{ }^{a}\right)$ to generate the direction of motion of $\left(x_{p}{ }^{a}, \lambda_{p}{ }^{a}\right)$, which is depicted by an arrow in the figure. Then use the initial condition $x_{p}{ }^{a}(0)=0$ and the terminal condition in (11.4) together with the arrows depicting the direction of motion to determine the optimal paths of $\left(x_{p}{ }^{a}, \lambda_{p}{ }^{a}\right)$ (Caputo, 1990b).

\section{a) Price of Agricultural Product}

Differentiation of (11) with respect to the input price of the agricultural product and rearranging terms yields:

$$
\begin{aligned}
& \dot{\lambda}_{p}{ }^{a}=a_{11}\left(t, \beta^{0}\right) \lambda_{p}{ }^{a}+a_{12}\left(t, \beta^{0}\right) x_{p}{ }^{a}, \\
& \dot{x}_{p}{ }^{a}=a_{21}\left(t, \beta^{0}\right) \lambda_{p}{ }^{a}+a_{22}\left(\mathrm{t}, \beta^{0}\right) x_{p}{ }^{a}-h_{L}\left(t, \beta^{0}\right) \frac{d \hat{L}}{d p^{a}}\left(t, \beta^{0}\right), \\
& x_{p}{ }^{a}(0)=0, \text { and } \\
& \lambda_{p}{ }^{a}\left(T^{0}\right)=0
\end{aligned}
$$

where

$$
\begin{aligned}
& a_{11}\left(t, \beta^{0}\right) \equiv r+h_{x}\left(t, \beta^{0}\right)-F_{x}\left(t, \beta^{0}\right)>0, \\
& a_{12}\left(\mathrm{t}, \beta^{0}\right) \equiv\left(\lambda-p^{f}\right) h_{x x}\left(t, \beta^{0}\right)-\lambda F_{x x}\left(t, \beta^{0}\right)>0, \\
& a_{21}\left(t, \beta^{0}\right) \equiv-h_{L}\left(t, \beta^{0}\right) \frac{d \hat{L}}{\mathrm{~d} \lambda}\left(t, \beta^{0}\right)>0, \text { and } \\
& a_{22}\left(t, \beta^{0}\right) \equiv F_{x}\left(t, \beta^{0}\right)-h_{x}\left(t, \beta^{0}\right)<0 .
\end{aligned}
$$

In signing $\mathrm{a}_{11}$ and $\mathrm{a}_{22}$, we make an additional assumption that $F_{\mathrm{x}}<0$. This implies that harvesting of forest resources takes place to the right of the Maximum Sustainable Yield (MSY). Thus, the following results are valid only for forests which have equilibrium stock levels greater than at MSY. This assumption is plausible since, typically, it is relatively undisturbed forests that are designated for protection where stock levels are likely to be greater than at MSY. Assuming that the solution to (12) denoted by $\lambda_{p}{ }^{a}\left(t, \beta^{0}\right)$ and $x_{p}{ }^{a}\left(t, \beta^{0}\right)$ exists and is continuous in $(t, \beta) \forall(t, \beta) \in[0, T)$, the functions $\lambda_{p}{ }^{a}\left(t, \beta^{0}\right)$ and $x_{p}{ }^{a}\left(t, \beta^{0}\right)$ describe the impact of changes in the market price of the agricultural commodity on the entire optimal path of forest resource stock and its current shadow price. Proposition 1 below summarizes the qualitative properties of this variational differential equation system (12). 


\section{Proposition 1:}

(a) $x_{p}^{a}\left(t, \beta^{0}\right) \geq 0 \forall t \in\left[0, T^{0}\right]$.

(b) $\lambda_{p}{ }^{a}\left(t, \beta^{0}\right) \leq 0 \forall t \in\left[0, T^{0}\right]$.

The diagrammatic proof of Proposition 1 is contained in Figure 1. Note that the optimal path given in Figure 1 represents one of many possible paths. It shows that an increase in the price of the agricultural product will lead to a higher equilibrium forest resource stock in the entire optimal path. Intuitively, a higher price of agricultural product leads to increased labor employment in farming, and hence a reduced labor allocation in forestry and a reduced harvest of forest products. This in turn increases the forest stock, ceteris paribus. A higher residual forest stock at equilibrium yields a lower shadow value of the forest stock. This result seems contradictory to the commonly held perception that lower agricultural prices in developing countries help protect rainforests (Deacon, 1995) through tax policies that keep agricultural output prices low and thereby provide disincentives for the expansion of agriculture. What we show here is that when conversion of forest lands is controlled, better prices for farm products promote forest conservation by diverting people from extractive activities in the forest.

\section{b) Price of Agricultural Inputs}

Differentiation of (11.1-11.4) with respect to price of the agricultural input and rearranging terms gives:

$$
\begin{aligned}
& \dot{\lambda}_{p}{ }^{I}=a_{11}\left(t, \beta^{0}\right) \lambda_{p}{ }^{I}+a_{12}\left(t, \beta^{0}\right) x_{p}{ }^{I}, \\
& \dot{x}_{p}{ }^{I}=a_{21}\left(t, \beta^{0}\right) \lambda_{p}{ }^{I}+a_{22}\left(t, \beta^{0}\right) x_{p}{ }^{I}-h_{L}\left(t, \beta^{0}\right) \frac{\mathrm{d} \hat{L}}{\mathrm{~d} p^{I}}\left(t, \beta^{0}\right), \\
& x_{p}{ }^{I}(0)=0, \text { and } \\
& \lambda_{p}{ }^{I}\left(T^{0}\right)=0 .
\end{aligned}
$$

The qualitative properties of the variational differential equation (13.1-13.4) are summarized in Proposition 2 and the results are given in the perturbed phase diagram in Figure 2. 


\section{Proposition 2:}

(a) $x_{p}{ }^{I}\left(t, \beta^{0}\right) \leq 0 \forall t \in\left[0, T^{0}\right]$.

(b) $\lambda_{p}{ }^{I}\left(t, \beta^{0}\right) \geq 0 \forall t \in\left[0, T^{0}\right]$.

Intuitively, an increase in the agricultural input price reduces returns from farming, which in turn reduces labor use in agriculture. The extra labor released is transferred to forest extraction resulting in higher harvests and a lower equilibrium resource stock and a higher shadow price.

\section{c) Knowledge of Agricultural Production Techniques}

As above, differentiation of (11.1-11.4) with respect to $\alpha(t)$, the coefficient representing agricultural knowledge and rearranging terms gives:

(14.1) $\dot{\lambda}_{\alpha}=a_{11}\left(t, \beta^{0}\right) \lambda_{\alpha}+a_{12}\left(t, \beta^{0}\right) x_{\alpha}$,

(14.2) $\dot{x}_{\alpha}=a_{21}\left(t, \beta^{0}\right) \lambda_{\alpha}+a_{22}\left(t, \beta^{0}\right) x_{\alpha}-h_{L}\left(t, \beta^{0}\right) \frac{\mathrm{d} L}{\mathrm{~d} \alpha}\left(t, \beta^{0}\right)$,

$$
\begin{aligned}
x_{\alpha}(0) & =0, \text { and } \\
\lambda_{\alpha}\left(\mathrm{T}^{0}\right) & =0 .
\end{aligned}
$$

The qualitative properties of the above variational differential equation system are summarized in Proposition 3 and the results are shown in Figure 3.

\section{Proposition 3:}

(a) $x_{\alpha}\left(t, \beta^{0}\right) \geq 0 \forall t \in\left[0, T^{0}\right]$.

(b) $\lambda_{\alpha}\left(t, \beta^{0}\right) \leq 0 \forall t \in\left[0, T^{0}\right]$.

This case is analogous to that of an increase in the price of the agricultural product. Better technical know how in farming increases profits and leads to an increase in labor use. This reduces labor use in the forestry sector, lowering harvests, increasing the forest stock, and lowering its shadow price.

\section{d) Discount Rate}

Again, differentiation of (11) with respect to the discount rate and rearranging terms results in:

$$
\begin{aligned}
& \dot{\lambda}_{r}=a_{11}\left(t, \beta^{0}\right) \lambda_{r}+a_{12}\left(t, \beta^{0}\right) x_{r}, \\
& \dot{x}_{r}=a_{21}\left(t, \beta^{0}\right) \lambda_{r}+a_{22}\left(t, \beta^{0}\right) x_{r}-h_{L}\left(t, \beta^{0}\right) \frac{d \hat{L}}{d r}\left(t, \beta^{0}\right), \\
& x_{\alpha}(0)=0, \text { and }
\end{aligned}
$$




$$
\lambda_{\alpha}\left(T^{0}\right)=0
$$

The qualitative properties of (15) are summarized in Proposition 4 and the results are shown in Figure 4.

\section{Proposition 4:}

(a) $x_{r}\left(t, \beta^{0}\right) \leq 0 \forall t \in\left[0, T^{0}\right]$.

(b) $\lambda_{r}\left(t, \beta^{0}\right) \leq 0 \forall t \in\left[0, T^{0}\right]$.

By reducing the opportunity cost of present harvests relative to future harvests, higher interest rates will increase quantity harvested and lower the equilibrium stock of forest resources as well as its shadow price.

\section{e) Price of Forest Products}

Finally, differentiation of (11) with respect to the price of the forest product and rearranging the terms results in the following system of variational differential equations:

$$
\begin{aligned}
& \dot{\lambda}_{p}{ }^{f}=a_{11}\left(t, \beta^{0}\right) \lambda_{p}{ }^{f}+a_{12}\left(t, \beta^{0}\right) x_{p}{ }^{f}-h_{x}\left(t, \beta^{0}\right), \\
& \dot{x}_{p}{ }^{f}=a_{21}\left(t, \beta^{0}\right) \lambda_{p}{ }^{f}+a_{22}\left(t, \beta^{0}\right) x_{p}{ }^{f}-h_{L}\left(t, \beta^{0}\right) \frac{d L}{d p^{f}}\left(t, \beta^{0}\right), \\
& x_{p}{ }^{f}(0)=0, \text { and } \\
& \lambda_{p}{ }^{f}\left(T^{0}\right)=0 .
\end{aligned}
$$

The qualitative properties of (16) are summarized below and the results are shown in Figure 5.

\section{Proposition 5:}

(a) $x_{p}{ }^{f}\left(t, \beta^{0}\right) \frac{\leq}{>} 0 \forall t \in\left[0, T^{0}\right]$.

(b) $\lambda_{p}{ }^{f}\left(t, \beta^{0}\right) \geq 0 \forall t \in\left[0, T^{0}\right]$.

Proposition 5 suggests that the effect of an increase in the price of the forest product on the stock is indeterminate. It is obvious that higher output prices will increase labor allocated to extractive activities. However, higher product prices also result in a higher shadow price of the forest resource thus increasing the opportunity cost of present extraction, which in turn will reduce the quantity extracted. It is not immediately clear which effect - the profit motive arising from higher prices or the 
conservation motive from the increased opportunity cost - will predominate. It can be shown that at high enough values of the interest rate, the former effect dominates and higher prices lead to a reduction in the equilibrium forest stock.

\section{An Empirical Illustration}

In order to conduct an empirical analysis of the effect of the exogenous parameters on forest conservation, ideally, one would use data on forest growth functions, agricultural production and relevant cost and price information. However, the type of data required for such an exercise is mostly unavailable. For instance, although growth data for certain tropical timber species may be available, data on the growth of non-timber forest products (NTFP) is hard to obtain. Discussions with biologists and forest ecologists indicate that the generation of biological growth data for NTFP species is time consuming and prohibitively expensive. Moreover, the harvest function specified in the above model requires labor allocation data on forest resource extraction as well as stock data for forest resources. Accurate labor allocation data can only be collected using participatory research approaches. Although data collected through anthropological surveys on labor allocation for forest resource extraction in the study area is available, this data is limited to only a few households and, therefore, may not adequately represent the forest dwelling population. Given these constraints on data availability, we provide limited empirical support for the analytical results obtained above by conducting an econometric analysis. We show that the harvest rate for forest resources can be explained reasonably well by the exogenous parameters of the model. As postulated in the theoretical model, the harvest rate for forest products can be expressed as

$$
h(t)=f\left(x(t), p^{a}, p^{f}, p^{I}, r, \alpha, K, \gamma\right) .
$$

That is, the harvest rate is a function of the stock of forest resources, prices of agricultural product and inputs, interest rate, level of knowledge, the carrying capacity of the forest and the intrinsic growth rate of the forest stock. A modified version of the above equation was estimated using primary data collected in the Sinharaja forest reserve in Southern Sri Lanka. The biological richness of the Sinharaja forest has drawn the attention of the national and international conservation community. In 1978, it was declared a Man and Biosphere Reserve by the United Nations Educational, Scientific, and Cultural Organization (UNESCO). In 1988, UNESCO recognized Sinharaja as a World Heritage Site. Sinharaja is the only remaining relatively large (11,000 ha) and less disturbed Tropical Humid Wet Evergreen Forest in Sri Lanka. Nine of the 15 floristic regions in the country are located in this forest. Ninety five percent of endemic birds, and $70 \%$ of endemic woody plants are believed to exist in the Sinharaja (Gunatilleke and Gunatilleke, 1980). An estimated 1,363 forest dependent households live in the periphery of the forest. These villagers depend on forest resources to 
a varying degree. McDermott et al. (1990) have identified 223 distinct plant species which are used by villagers. The biological richness and the long history of close interaction between the forest and the neighboring communities makes Sinharaja an ideal site for empirical verification of the theoretical predictions presented earlier.

An initial field survey was carried out in the peripheral villages of the Sinharaja forest during the period May-December, 1996. Another field visit to all the households was made during June-July, 1997 to verify specific details and to collect missing information. The survey included information on household economic data, quantities and prices of all NTFP collected by the local population, detailed information on agricultural activities of the households, and the attitudes of the heads of households towards forest conservation. A total of 305 households were originally selected using a stratified random sampling procedure. The sample was stratified to three districts lying at the boundary of the forest - consisting of a set of 98, 98, and 109 households in the Ratnapura, Galle, and Matara districts, respectively. A list of forest dependent households for all three districts was developed based on a rapid rural appraisal conducted prior to the survey. Random number tables were then used to select individual households from each district. The total sample included 11 villages. Of these, one was dropped from the sample due to difficulties in obtaining accurate information on their extractive activities. A Forest Department camp was found to be permanently located in this village and we found that villagers were loath to reveal information on forest resource extraction. During the second visit, for a variety of reasons, enumerators were unable to contact 23 households. These households were dropped from the sample. Another 11 households were excluded due to observed inconsistencies in their responses. After excluding these observations the final analysis was carried out for 256 households.

In estimating (17), the forest stock $x(t)$, carrying capacity $K$, and intrinsic rate of growth of the forest $\gamma$ were dropped due to a lack of data on these variables. This omission of relevant variables from the regression equation makes the estimates biased (Greene, 1993). However, since Sinharaja is a relatively small forest (about 11,000 ha), there may not be enough spatial variation in forest resource stock and carrying capacity in a cross sectional study. Another problem encountered in the estimation was the large number of forest products being collected by the households. The survey reported that 84 different plant and animal products were being collected by the villagers. These products include fruits and vegetables, yams, mushrooms, spices, construction materials, rattan, bamboo, medicinal plants, parts of various plants used in rural households for fencing and other agricultural activities, game animals, ornamental plants, and fish and kithul products. Kithul (Caryota urens) is a palm tree which is tapped for its sap. Kithul sap provides three products, namely-Jaggerry (a local candy), honey and a local beer. Extraction of forest products has been legally prohibited in Sinharaja since it was declared a protected area. However the Sri Lanka Forestry Sector Master Plan published by the Ministry Of Forestry and Environment (1995) recommended the use of NTFP by local communities in the vicinity of protected forests. As a result, the Forest Department issues permits for extraction of 
kithul products. Extraction of other products is still legally prohibited. However, these laws are loosely enforced. According to the our survey, $78.7 \%$ of the cash income from NTFP comes from kithul products. Apart from kithul, cardamom (Elettaria cardamomum), rattan (Calamus spp), weniwel (Coscinium fenestratum, a medicinal plant) and bamboo (Bambusa vulgaris) were the main NTFP products which contributed to cash income in Sinharaja in previous years (McDermott et al., 1990). However, the relative contribution of the other forest products has declined over time due to changing lifestyles, restrictive regulation and depletion of forest stocks. Since kithul is the main NTFP that earns cash income at present, we use the quantity of kithul products extracted as the dependent variable. Aggregation over different kithul products such as honey and local beer was performed by converting their quantities to Jaggerry units based on the quantity of kithul sap required for each product. This aggregated amount of Jaggerry was used in the analysis.

In the empirical analysis, the variables $p^{f}$ and $p^{a}$ were dropped because of inadequate variation in the data. Therefore, gross agricultural income was used as a proxy for farming activities. As discussed earlier, the interdependence between forestry and farming sectors occurs due to competing labor allocation between the two activities. Thus the quantity of land available to the household determines the amount of labor used for agriculture. Therefore, in addition to gross agricultural income, the total amount of land owned by the household (land endowment) was used as an independent variable. Agricultural input prices also did not show adequate variation in the survey results. Therefore, the distance to the nearest town was used as a proxy for agricultural input prices. This variable reflects the opportunity cost of time and other resources needed to buy agricultural inputs and transport them from the town to the survey villages. Agricultural knowledge was measured by two variables: the formal education level of the head of the household and the degree of extension education. Formal education was measured as: no schooling, cannot read and write (1), no schooling, can read and write (2), Grades 1-5 (3) Grades 6-10 (4) General Certificate of Education - Ordinary Level (GCE, O/L) (5) GCE Advanced Level (6), and finally, Degree or Diploma (7). The GEC (O/L) is an examination conducted nationwide for 10th grade students and it is considered the basic qualification for a government or private sector job. The GCE Advanced Level (A/L) is the university entrance examination. Extension education was measured by the number of visits made per year by extension agents from the local agricultural development agencies - the Department of Agriculture, Tea Research Institute, Tea Small Holdings Authority and the Department of Export Agriculture. The distance from the house to the forest was also used as an independent variable. This variable is related to the labor spent on forest extraction. Part of the total amount of time spent on extraction is used to travel to the forest. When villagers have to travel a longer distance to the forest, it works as a disincentive for extractive activities. Although the distance variable is not significant in terms of forest protection policy, inclusion of this variable avoids specification errors due to omission of variables since it can explain some of the variation in the dependent variable. 
A somewhat crude field experiment was carried out to measure the time preference of the head of the household. The respondents were informed that they will be given Rs. 75 (US\$1.25) now or Rs. 100 (US\$1.67) after 7 days for participation in the survey. If the respondent was willing to wait another week to get Rs. 100 his/her time preference was rated as low (1). If the respondent wanted to have the money now, the amount payable after one week was raised to Rs. 125 (US\$2.08) and if the respondent still insisted in having it the same day, his time preference was rated as high (3). If the respondent was willing to wait a week when the amount was raised to Rs. 125 , his time preference was rated as average (2). In order to avoid problems created by hypothetical situations, actual monetary payments were made based on the responses of the individuals.

\section{Results}

The total sample included 1,226 individuals. On average, a household has 4.8 members. Of the total sample, about $49 \%$ were females. About $55 \%$ of the individuals in the sample participate in the labor force and $65 \%$ of them identified their occupation as farming. Only $78(6.9 \%)$ of the total individuals in the sample were employed in the private sector or in the government. About 170 $(13.8 \%)$ individuals did not receive any education while the rest have had some formal education. Only $110(8.9 \%)$ individuals in the sample have passed the GCE $(\mathrm{O} / \mathrm{L})$ examination.

On average $23.9 \%$ of the household income is derived from NTFP and the minimum and maximum contribution of NTFP to household income were $0.06 \%$ and $80.7 \%$ respectively. As mentioned earlier, kithul is the most significant forest product in terms of the proportion of cash income. Of the 256 households surveyed, only 130 (50.8\%) households reported gathering kithul products. An Ordinary Least Squares (OLS) regression with zeros for the households which do not collect kithul products will result in inconsistent estimates. On the other hand taking only the nonzero values may lead to sample selection bias (McDonald and Moffit, 1980). Therefore, a tobit analysis was performed. Since the tobit procedure does not have a capacity for diagnosis of data problems, an OLS regression was carried out first. OLS results revealed values of $R^{2}=0.23$ and a significant F-value (10.65) for the overall goodness of fit at a 5\% significance level. Examination of the correlation matrix of independent variables suggested that there was no potential for severe multicollinearity. Diagnostic tests, however, revealed the presence of heteroscedasticity. Harvey and Glejser tests gave Chi-square values of 38.26 and 43.65 respectively. The critical Chi-square value for 7 degrees of freedom was 14.07 at a 5\% significance level. Therefore a heteroscedastic tobit model was estimated, results for which are given in Table I.

The heteroscedastic tobit procedure does not provide a measure for the overall goodness of fit. The predicted probability of the dependent variable values being greater than zero given average values of the independent variables was 0.4872 against the observed probability of 0.5078 . The value of the log likelihood function for the regression was -1060.2 . 
As shown in the table, the results are largely consistent with the theoretical predictions. Agricultural income shows a statistically significant negative relationship with respect to the level of forest extraction. People who have to walk long distances to get to the forest to collect resources extract smaller quantities. Formal education shows a postulated negative relationship to the level of extraction. However, this relationship could not be established statistically. Therefore, there is no evidence to suggest that higher levels of formal education decrease extraction of forest products. Agricultural extension, however, shows the expected relationship with statistical significance. That is, adult education provided through extension services improves the knowledge of agricultural production techniques and, in effect, reduces dependency on forest resources. The rate of individual time preference shows the expected positive impact on extraction level. This variable is significant at the $\alpha=0.1$ level. Note, however, that the probability value is only slightly above 0.05 . Land resource endowment is negatively related to the extraction level, as is to be expected. This relationship is not statistically significant. This is probably due to the impact of widely diverse forms of tenure arrangements existing in the study area. Various forms of land tenancy, lease arrangements and sharing of land among family members were observed. In collecting data on land endowment, tenancy details were left out of the survey. This omission may have resulted in the statistically insignificant result. Distance of households to the market shows an unexpected sign and the result is statistically insignificant. It may imply that distance to the market may not be a good proxy for agricultural input prices.

\section{Summary and Policy Implications}

We have shown that higher (lower) agricultural output (input) prices, better know-how in agricultural production, and low individual time preference results in a higher stock of forest resources in the entire optimal path over the planning horizon. These results are robust as they are not confined to the neighborhood of the steady state. Empirical analysis with primary data from the Sinharaja Forest Reserve provides supplementary evidence for these theoretical predictions. Altogether, these results suggest that agricultural development in the peripheral villages of the protected tropical rainforests may be a useful way to conserve forest resources and therefore protect biodiversity.

These findings suggest that policy makers should consider the development of agriculture in the periphery of protected forests as an integral component of forest conservation programs. Traditional approaches such as the Integrated Conservation and Development Projects (ICDP) promoted by the United Nations and other international agencies have focused on less ecologically harmful utilization of forest resources while generating income for the local communities so that they will take the initiative to protect resources that provide for their livelihood (Barret and Arcese, 1995; Simpson, 1995). Even if the ICDP strategy is commercially successful and is able to compensate forest communities for income losses suffered due to forest protection, the question whether the local 
people will voluntarily take steps to protect forest resources remains open. Apart from this leap of faith, past experience shows that these strategies have failed to generate an adequate income at the local level. For example, recent studies suggest that values generated by biodiversity prospecting are likely to be negligible (Simpson, 1995; Simpson, et al., 1996). Royalties and other up-front payments generally go to pay for the taxonomic and processing expertise of the collector and only a minuscule proportion of the revenues from biodiversity prospecting may accrue to the local communities, if at all. Most of the expenditure incurred by tourists, in the case of eco-tourism, for instance, goes to airlines, hotels, ground transportation and other services. Thus, of the huge revenues that can potentially be earned from eco-tourism, a minute amount may only be spent at the site. Infrastructure, institutions, and trained personnel are generally not available at the local level to capture even a relatively small fraction of these revenues. Compensation for machinery, fuel, and packaging also absorb considerable portion of NTFP revenues (Simpson, 1995). Therefore, biodiversity prospecting, eco-tourism and sustainable harvesting of NTFP may not provide adequate income at local levels and in turn, may not provide incentives for local communities to protect the forest stock. Supplementing the income of local communities through agriculture, on the other hand, will divert people away from forest gathering activities and thereby preserve forest resources.

Another important advantage of the approach proposed in this paper is that it reduces the need for costly ecological monitoring of protected forests. Traditional forest protection strategies depend on forest resource utilization as a means to compensate peripheral communities. Implementing this approach eventually leads to the question of the sustainability of forest resource use and associated ecological monitoring. Ecological monitoring of dense tropical rainforests can be complex, prohibitively expensive and generally ineffective in the face of forest resource extraction due to the ever-changing dynamics of tropical ecosystems and a large number of people extracting forest resources on an irregular basis over a vast area (Barret and Arcese, 1995, Leader-Williams and Albon, 1990). Most forest departments do not have the skilled manpower or other resources to engage in this task. In contrast to using forest resources for compensation of welfare losses, the proposed strategy aims at reducing villagers' dependency on forest resources, and, hence the case for intensive ecological monitoring is diminished. Moreover, conservation strategies such as eco-tourism, biodiversity prospecting and sustainable use of forest products are all relatively new concepts and donor agencies and other national and international development agencies have limited experience in their implementation. However, the same agencies have access to vast amounts of accumulated knowledge on agricultural development in the tropics which can be drawn upon for protection of forest resources and biodiversity.

One possible drawback of agricultural development, however, may be the encroachment of farming into protected forest lands. This can be avoided through implementing agricultural development policies together with legislative measures that prevent conversion of forest land to farming. The latter component may require monitoring and policing resources, although this type of 
monitoring may be far cheaper than the more complicated task of controlling forest extraction on a daily basis. Another issue that we have not addressed and may require policy attention is the possibility of migration of people from other areas who are lured by the improved profitability of farming. This could increase pressure on the protected forest and dilute the benefits of the proposed policy. 


\section{References}

Barret, C. B. and Arcese, P. "Are Integrated Conservation-Development Projects

Sustainable?: On the Conservation of Large Mammals in Sub-Saharan Africa." World Development, 1995, 23(7), pp.1073-84.

Buchholz, R A. Principles of Environmental Management: The Greening of Business. New Jersey: Prentice Hall, 1993.

Caputo, M. R. "How to Do Comparative Dynamics on the Back of an Envelope in Optimal Control Theory." Journal of Economic Dynamics and Control, 1990a, 14(3), pp. 655-83.

Caputo, M. R. "Fundamental Symmetries and Qualitative Properties in the Adjustment Cost Model of the Firm." Journal of Mathematical Economics, 1992, 21(2), pp. 99-112.

Deacon, R. T. "Assessing the Relationship Between Government Policy and

Deforestation." Journal of Environmental Economics and Management, 1995, 28(1), pp. 1-18.

Ehui, S. K.; Hertel, T. W. and Preckel, P. V. "Forest Resource Depletion, Soil Dynamics, and Agricultural Productivity in the Tropics." Journal of Environmental Economics and Management, 1990, 18(2), pp. 136-154.

Gale, D. and Nikaido, H. "The Jacobian Matrix and Global Univalence of Mappings."Mathematical Annals, 1965, 159(1), pp. 81-93.

Ghimire, K.B. "Parks and People: Livelihood Issues in National Park Management in Thailand and Madagascar". Development and Change, 25, pp. 195-229.

Gunatilake, H. M. "The Role of Rural Development in Protecting Tropical Rainforests: Evidence from Sri Lanka”, Journal of Environmental Management, 1995, 53, pp. 273-292.

Gunatilleke, C.V.S. and Gunatilleke, I. U. A. N. "Floristic Composition of Sinharaja: A Rain Forest in Sri Lanka with Special Reference to Endemics." The Sri Lanka Forester, 1980, 14(1), pp. 171-179.

Guppy, N. “Tropical Deforestation: A Global View.” Foreign Affairs, 1984, 62(4), pp. 928-65.

Hough, J.L "Obstacle to Effective Management of Conflicts Between National Parks and Surrounding Communities in Developing Countries". Environmental Conservation, 15, pp. 129-135.

LaFrance, J T. "Do Increased Commodity Prices Lead to More or Less Soil Degradation." Australian Journal of Agricultural Economics 1992, 36(1), pp. 57-82.

Leader-Williams, N.; Albon, S. D. and Berry, P. S. "Illegal Extraction of Black Rhinos and Elephant Populations: Pattern of Decline, Law Enforcement, and Patrol Efforts in Luangwa Valley, Zambia." Journal of Applied Ecology 1990, 27(3), pp. 1055-87.

McDermott, M.; Gunatilleke, C.V.S. and Gunatilleke, I. A. U. N. "The Sinharaja Rain Forest: Conserving both Biological Diversity and a Way of Life." The Sri Lanka Forester, (1990), 19(1), pp. $3-22$.

McDonald, J .F. and Moffit, R.A. "The Uses of Tobit Analysis." The Review of Economics and Statistics, 1980, 62(2), pp. 318-21.

Ministry Of Forestry and Environment, Government of Sri Lanka, Forestry Sector Master Plan (1995). Colombo. 
Nepal, S. K. and Weber, K. E. "Managing Resources and Resolving Conflicts: National Parks and Local People". International Journal of Sustainable Development and World Ecology", 2, pp. 11-25.

Panayotou, T. "Conservation of Biodiversity and Economic Development. The Concept of Transferable Development Rights.” Environmental and Resource Economics, 1994, 4(1), pp. 91-110.

Poore, D. and Sayer, J. The Management of Tropical Moist Forest Lands: Ecological Guidelines. Gland, Switzerland and Cambridge, U. K.: International Union for Conservation of Nature, 1991.

Repetto, R. The Forest for the Trees: Government Policies and the Misuse of Forest Resources. Washington DC: World Resources Institute, 1988.

Repetto, R. and Gillis, M. Public Policies and Misuse of Forest Resources. New York: Cambridge University Press, 1988.

Repetto, R. "Deforestation in the Tropics". Scientific American, 1990, 262(4), pp. 36-42.

Simpson, D. R. "Why Integrated Conservation and Development Projects May Achieve Neither Goals?.” Discussion Paper 95-20, Washington DC: Resources for the Future, 1995.

Simpson, D. R.; Dedjo, R. A. and Reid, J. W. "Valuing Biodiversity for Use in Pharmaceutical Research." Journal of Political Economy, 1996, 104(1), pp. 163-85.

Studsrod, J. E. "Park People Relationship: The Damages Caused by park Animals Around the Royal Bardia National Park, Nepal”. Environmental Conservation, 22, pp. 133-142.

United Nations Environment Program. Global Biodiversity Assessment. Cambridge: Cambridge University Press, 1995.

Wells, M. "Biodiversity Conservation, Affluence, and Poverty: Mismatched Costs and Benefits and Efforts to Remedy Them." Ambio, 1992, 21(3), pp. 237-43.

World Bank. Strategy for Forest Sector Development in Asia. World Bank Technical Paper Number 182, Washington DC: The World Bank, 1993.

World Resources Institute. World Resources, 1994-95: A Guide to the Global Environment. New York: Oxford University Press, 1994. 


\section{Appendix}

Total differentiation of (7.1) and (7.2) yields A1. Note that in signing the determinant of $\mathrm{B}$, in addition to the assumptions given in equations (2) and (3), $\left(\mathrm{p}^{\mathrm{f}}-\lambda\right)>0$, and $Q_{\text {LaLa. }} Q_{I I}-Q^{2}{ }_{\text {LaI }}>0$ established in the text are used:

(A1)

$$
A+B\left(\begin{array}{l}
\frac{\partial \hat{I}}{\partial p^{a}} \frac{\partial \hat{I}}{\partial p^{f}} \frac{\partial \hat{I}}{\partial p^{I}} \frac{\partial \hat{I}}{\partial \alpha} \frac{\partial \hat{I}}{\partial \lambda} \\
\hat{\partial} \frac{\partial \hat{L}}{\partial p^{a}} \frac{\partial \hat{L}}{\partial p^{f}} \frac{\partial \hat{L}}{\partial p^{I}} \frac{\partial \hat{L}}{\partial \lambda}
\end{array}\right)=0
$$

where

$$
\begin{aligned}
& \mathrm{A}=\left(\begin{array}{ccccc}
\mathrm{Q}_{I} & 0 & -1 & p^{a} Q_{I \alpha} & 0 \\
-Q_{L a} & h_{L} & 0 & -p^{a} Q_{L \mathrm{La} \alpha} & -h_{L}
\end{array}\right) \text { and } \\
& \mathrm{B}=\left(\begin{array}{lr}
p^{a} Q_{I I}- & p^{a} Q_{I L a} \\
-p^{a} Q_{L a I} & p^{a} Q_{L a L a}+\left(p^{f}-l\right) h_{L L}
\end{array}\right) .
\end{aligned}
$$

The determinant of $\mathrm{B}$ is :

$$
\begin{aligned}
& |B|=P^{a} Q_{I I}\left\{P^{a} Q_{L a L a}+\left(p^{f}-\lambda\right) h_{L L}\right\}-\left(p^{a}\right)^{2}\left(Q_{L a I}\right)^{2} \\
& |B|=\left(p^{a}\right)^{2}\left\{Q_{L a L a .} Q_{I I}-\left(Q_{L a I}\right)^{2}\right\}+p^{a} Q_{I I}\left\{\left(p^{f}-\lambda\right) h_{L L}\right\}>0 .
\end{aligned}
$$




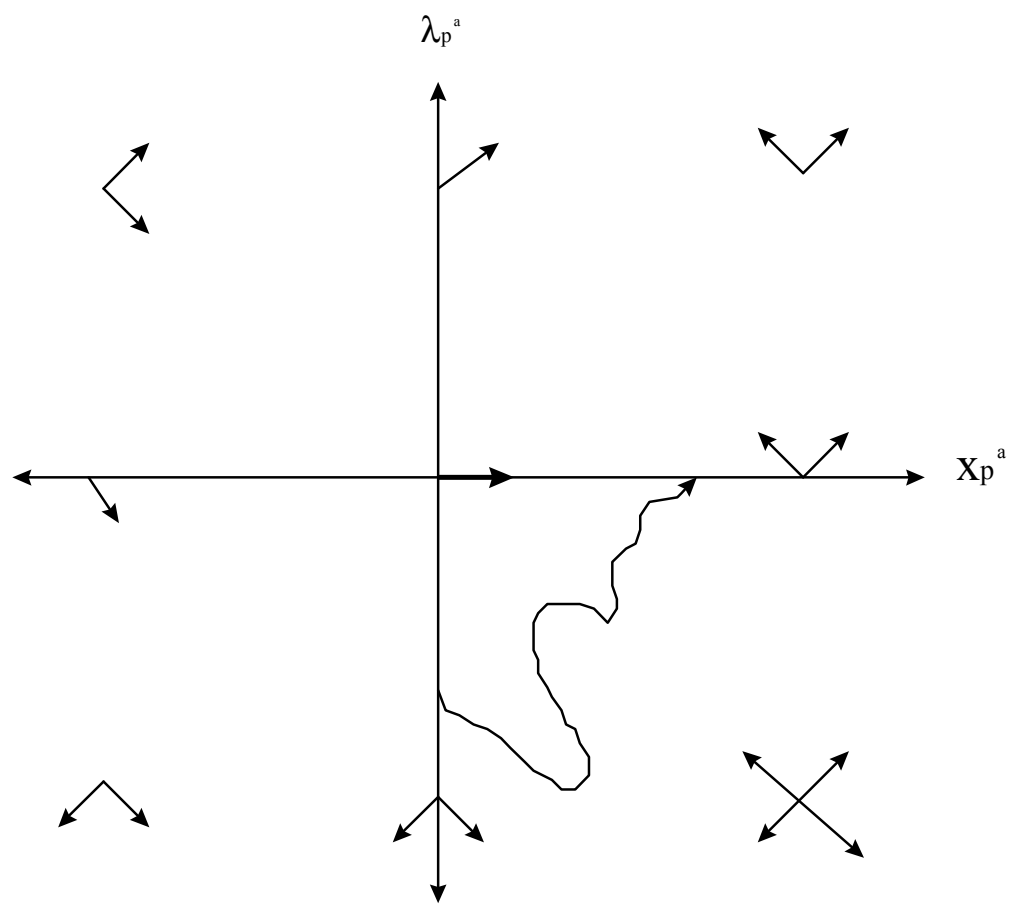

Figure 1. Perturbed phase diagram for changes in agricultural output price 


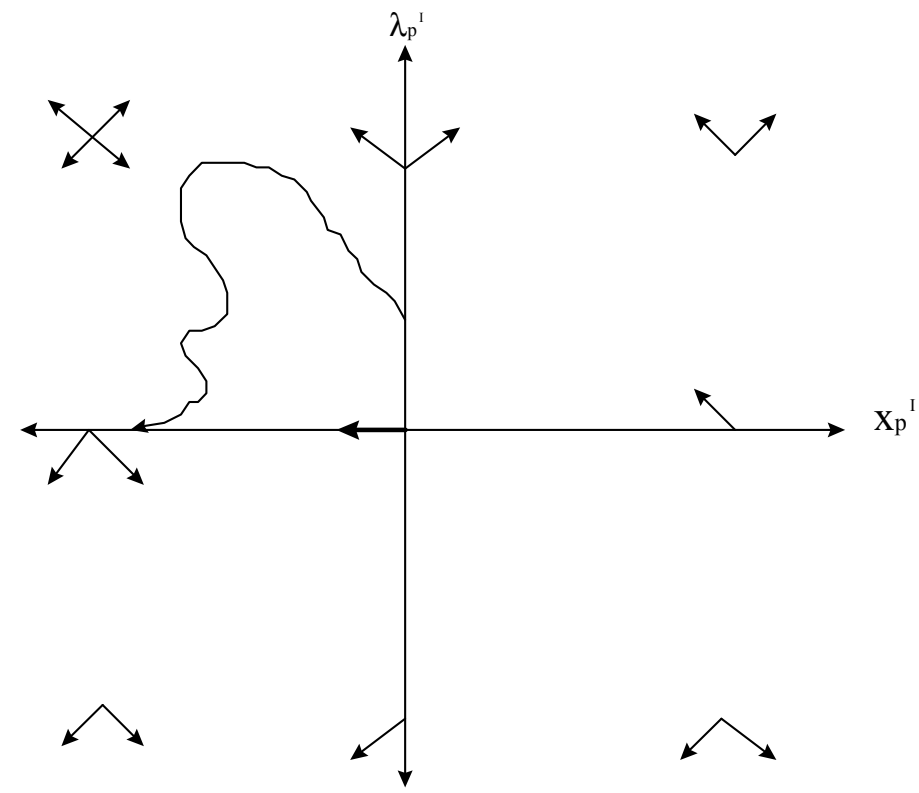

Figure 2. Perturbed phase diagram for changes in agricultural input price 


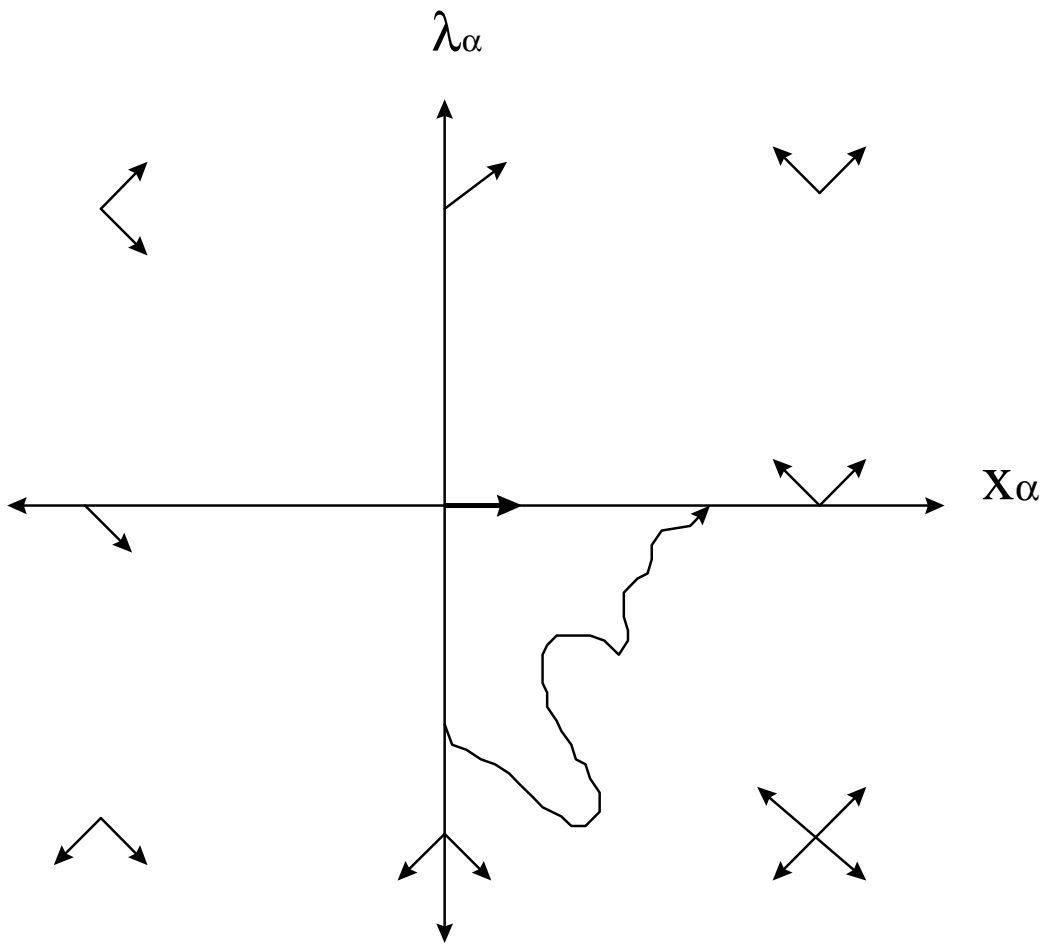

Figure 3. Perturbed phase diagram for changes in the knowledge of agricultural production techniques 


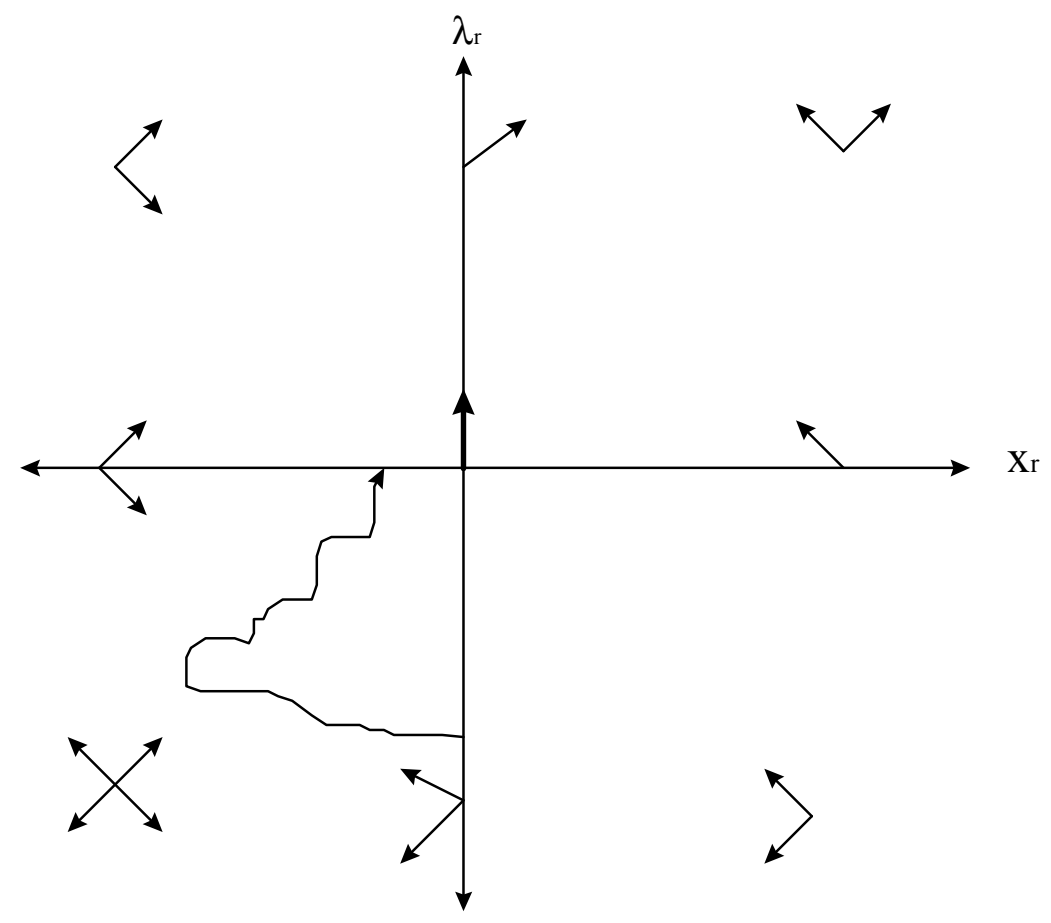

Figure 4. Perturbed phase diagram for changes in the discount rate 


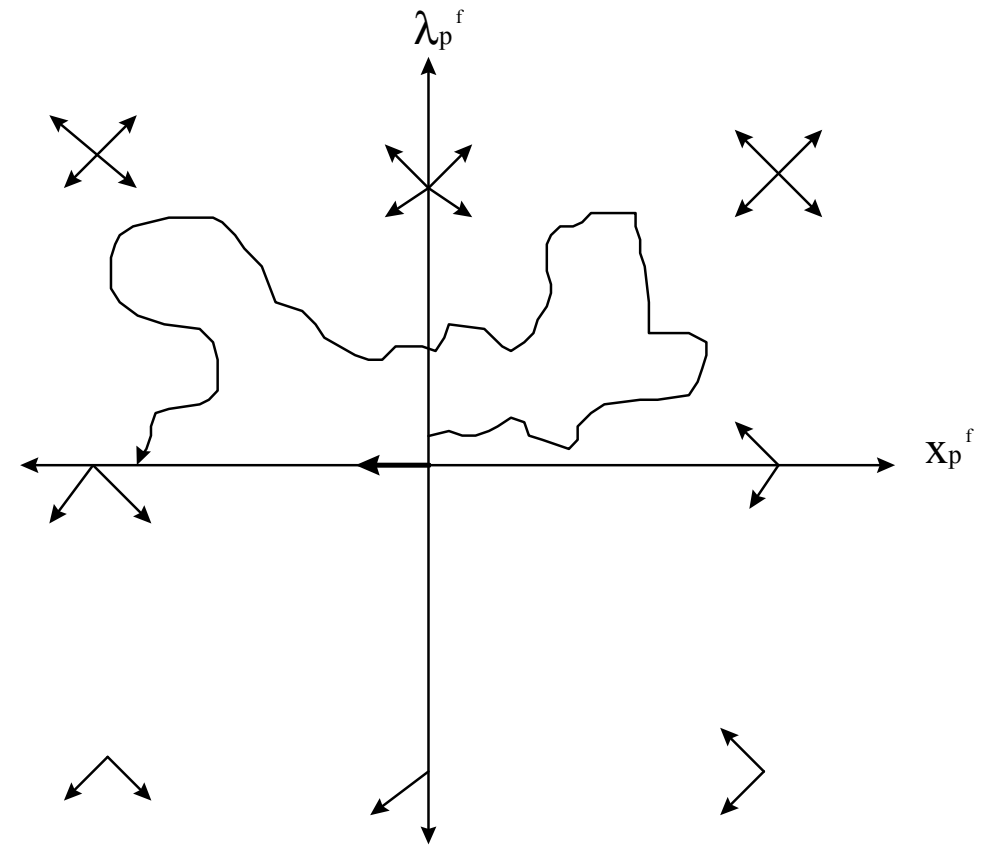

Figure 5. Perturbed phase diagram for changes in price of forest products 
Table I. Tobit regression results on the harvest rate of kithul products

\begin{tabular}{lcccc}
\hline Variable & Coefficient & $\begin{array}{l}\text { Standard. } \\
\text { Error }\end{array}$ & t-ratio & P value \\
Constant & 487.48 & 193.70 & $2.517^{* *}$ & 0.0118 \\
Agricultural income & $-0.30 \mathrm{E}-02$ & $0.87 \mathrm{E}-03$ & $-3.475^{* *}$ & 0.0005 \\
Distance to forest & -66.30 & 25.73 & $-2.577^{* *}$ & 0.0099 \\
Extension education & -14.64 & 5.57 & $-2.629^{* *}$ & 0.0085 \\
Education level & -4.03 & 30.05 & -0.134 & 0.8932 \\
Discount rate & 91.33 & 47.38 & $1.928^{*}$ & 0.0538 \\
Land endowment & -2.45 & 9.14 & -0.268 & 0.7883 \\
Distance to market & -9.10 & 26.15 & -0.348 & 0.7277 \\
\hline
\end{tabular}

Note: ${ }^{*}$ and ${ }^{* *}$ indicate significant levels of $\alpha=0.1$, and $\alpha=0.05$ levels, respectively. 